\title{
Valuation of Variable Long-term Care Annuities with Guaranteed Lifetime Withdrawal and Limited Hospitalization Coverage Benefits and Two Investment Funds
}

\section{Sara Moosavi}

Shahid Beheshti University

Amir T Payandeh ( $\sim$ amirtpayandeh@sbu.ac.ir)

Shahid Beheshti University

\section{Research Article}

Keywords: Long-term care, Life Care Annuity, Guaranteed Lifetime Withdrawal Benefit, hospitalization coverage

Posted Date: July 9th, 2021

DOl: https://doi.org/10.21203/rs.3.rs-663521/v1

License: (c) (i) This work is licensed under a Creative Commons Attribution 4.0 International License. Read Full License 


\title{
Valuation of Variable Long-term Care Annuities with Guaranteed Lifetime Withdrawal and Limited Hospitalization Coverage Benefits and Two Investment Funds
}

June 27, 2021

\begin{abstract}
Population aging on the one hand and increasing of expenditures for medical services via technology development on the other hand have created some problems for the insurance industry and have converted it into one of the most risky areas. Thus, it is obvious that designing the innovative product is one of the most basic needs in the field of health insurance. This study proposes a new variable annuity product that includes the benefits of guaranteed lifelong withdrawal benefit option, long-term care coverage and limited hospitalization coverage. This innovative product has been evaluated under two investment funds. A Monte Carlo algorithm has been employed to calculate the fair value of the product and numerical study has been conducted to illustrate the capability of this product. The innovative product may provide a more comprehensive solution for the aging problem of the population that is challenging in the current societies.
\end{abstract}

Keywords: Long-term care; Life Care Annuity; Guaranteed Lifetime Withdrawal Benefit; hospitalization coverage.

JEL classifications: G22; I1.

\section{Introduction}

Greater awareness of longevity risk and improvements in medical technology are two important reasons for the popularity of health care insurance products and the ever-increasing demand for such products. This study proposes a new variable annuity product that includes the benefits of guaranteed lifelong withdrawal benefit option, long-term care coverage and limited hospitalization coverage. 
The life care annuity (LCA) which is a combination of a long-term care (LTC) and lifetime annuity (LA) reduces the effect of strict underwriting process and adverse selection (Murtaugh, Spillman and Warshawsky, 2001; Webb, 2009; Brown and Warshawsky, 2013). Murtaugh et al. (2001) showed that the LCA reduces the cost of the LTC policy in some situations; therefore, more people can have access to it. They proved that the combination of a LTC and a LA can become more attractive through a positive correlation between mortality and disability. Webb (2009) maintained that the LCA products provide a more economical product than buying the LTC insurance and an annuity contract separately whenever there exists some management fees. In 2013, Brown and Warshawsky showed that in a situation where a significant portion of the population has been rejected by an insurance underwriting process, the LCA products are better than the LTC products from the insurer's viewpoint. On the other hand, D'Amato et al. (2020) proposed a de-risking strategy model for a LTC contract, by constructing hedge positions and computing the optimal hedge level for each strategies. Moreover, Di Palo (2020) proposed a variable life annuity which its benefits follows the observed mortality and the interest rates.

Insurance companies offer variable annuity products under some riders known as guarantees. These guarantees increase the insured's willingness toward purchasing such insurance policies. Insurance products with withdrawal guarantee which are known as products with Guaranteed Lifetime Withdrawal Benefit (GLWB) are very popular contracts. Several authors have introduced and evaluated some new products that are accompanied by GLWB option. For instance, Piscopo (2009) used the no arbitrage pricing theory to evaluate a variable annuity with Guaranteed Lifetime Withdrawal Benefits (VA-GLWB). Bernard (2010) proposed a methodology for determining the price of a GLWB where VA-GLWB is invested by a simple rate of return. Moreover, Holzet et al. (2012) proposed a life insurance contract that includes the benefit of Guaranteed Minimum Withdrawal (GMWB) option. They analyzed the effect of policyholders' behavior on the fair value of this rider embedded in different products. Piscopo and Haberman (2011) are the other authors who have offered a model for pricing of the VA-GLWB products under the Black-Scholes framework and described the effect 
of mortality risk on the value of the GLWB option. The Life Care Annuity-Guaranteed Lifetime Withdrawal Benefit (LCA-GLWB) is another new product that has been proposed by Hsieh et al. (2018) for the first time. Due to the complex calculation, they proposed a Monte Carlo algorithm that utilizes the variance reduction technique (Glasserman, 2004; Asmussen and Glynn, 2007).

Modeling the transition probability of the policyholder's health state is one of the most important steps to evaluate the above-mentioned products. Many authors have modeled their product by means of a Multi-state model based on the Markovian framework. For instance, Pitacco (1995, 2013, 2014) has offered a Multi-state model as a powerful tool for interpreting disability and the LTC insurances. Albarran et al. (2005) presented a new estimation method for a multiple state model and applied it to the disability insurance in Spain's aging population. Pritchard (2006) parameterized a multiple state model for the LTC and disability insurance contracts using the interval-censored longitudinal data. Also, he estimated costs of the LTC insurance contract for disabled people. Levikson and Mizrahi (2012) have analyzed a general Markovian multi-state model to describe the policyholder's changing demand over time. Baione and Levantesi (2014) employed a parametric multiple state model to study health insurance policies whenever data is limited and just the aggregated information on mortality and morbidity is available. Manton et al. (1993), Pitacco (1995), Haberman and Pitacco (1998), Murtaugh et al. (2001), Albarran et al. (2005), Pritchard (2006), Brown and Warshawsky (2013), Baione and Levantesi (2014) and Yang et al. (2016) have taken into account the continuous-time Markov processes to model the health status transition probability.

As mentioned earlier, the hospitalization coverage has been considered as a product's benefit in this study. Some authors purposed this kind of benefit as a single contract or a rider to other contracts. For example, Cochran et al.(2005) taken into account both the size and number of losses in a stochastic manner. They considered generalization of the collective risk model to evaluate the size of the population at risk as a nonlinear hierarchical growth model. Bharti (2006) proposed a multi-stage stochastic methodology to model inpatient bed unit utilizations in a given hospital. 
Tessera (2007) developed two probabilistic models for claim size in health insurance based on the claims of families and individuals covered by the policy. Rosenberg and Farrell (2008) employed a Bayesian statistical model to predict incidence and cost of hospitalizations for a given chronic disease. They assumed that the number of hospitalizations follows a Poisson distribution, with a lognormal prior for the mean number of hospitalizations day. Likewise, the cost per hospitalization may have a gamma distribution. Weng et al. (2012) focused on the problem of how to distribute resources among several hospitals to achieve a better operational efficiency for each hospital. Orji et al. (2014) estimated the cost of radiology procedures in a developing country by means of an activity-based costing model. Finally, Yang et al. (2017) proposed a pricing model that can evaluate fair premiums for limited coverage policies.

This study is organized as follows. Section 2 explains product details. Theoretical foundation of the product reviews in Section 3. Data explanation and numerical studies are addressed in Sections 4 and 5, respectively. Finally, Section 6 provides some brief conclusions and suggestions.

\section{Product specifications}

The health state of policyholders and their corresponding transition probability play fundamental roles in evaluation of an insurance health product. For simplicity, a seven-state continuous-time Markov process has been considered for classification of the individual's health status based on disability in performing instrumental activities of daily living (IADLs, including light housework, laundry, grocery shopping, meal preparation, getting around outside, money management, using the telephone) and activities of daily living (ADL, including eating (level 1), bathing (level 2), dressing (level 3), moving around (level 4), doing personal hygiene (level 5) and going to the toilet (level 6)), see Pritchard (2006), Haberman and Pitacco, (1998) for more details.

State of each policyholder begins from state 1 (healthy) and moves to state 2 (ADL level=1), state $3(\mathrm{ADL}$ level $=1$ and 2$)$, state $4(\mathrm{ADL}$ level $=3$ and 4$)$, state $5(\mathrm{ADL}$ level $=5$ and 6$)$, state 6 (stay at 
a hospital) and finally state 7 (death). Therefore, if $M_{x}(t)$ represents the state of the policyholder at time $t$ when $\mathrm{s}$ /he has bought the policy at age $x$, then the $7 \times 7$ transition probability matrix is given by $\boldsymbol{P}(x ; t)=\left[p_{i j}(x ; t)\right]$, where

$$
p_{i j}(x ; t)=P\left(M_{x}(t+s)=j \mid M_{x}(s)=i\right), i, j=1,2, \cdots, 7
$$

stands for the transition probability that the policyholder moves to state $j$ from state $i$ after a time t. This study follows Pritchard's (2006) recommendation for transition rates.

Figure 1 illustrates the seven-state model. At the beginning of the contract, an $x$ year old policyholder who is healthy, state 1 , pays $w_{0}^{x}$ to the insurance company. Therefore, the initial value of her/his account is equal to $w_{0}^{x}$. After withdrawing these costs at the beginning of year $t$, the insurer invests the rest of the amount in two investment funds. Moreover, it is assumed that $\delta$ percents of the amount is invested in a risky fund with the return rate $R_{t}$ in time $t$ and the rest (i.e., $1-\delta$ percents) is invested in a risk-free fund with the constant interest rate $i$. The obligations of the policy have withdrawn by the insurer's withdrawing and paying back to the policyholder at the beginning of year $t$. Some product assumptions are represented in the following.

$\left.A_{1}\right) S B_{t-1}^{x}$ denotes the insured's health care costs in the pervious year.

$\left.A_{2}\right) H B_{t-1}^{x}$, denotes the insured's hospitalization costs up to $L$ days during the whole contract's period in the previous year.

$\left.A_{3}\right) G_{t}$ denotes yearly random withdrawal benefits in year $t$ up to $\left.\beta w_{0}^{x}\right), \beta \in(0,1)$. Note that the policyholder determines the value of yearly random withdrawal benefits.

Furthermore, the insurer withdraws

$\left.A_{4}\right) \alpha W_{t}^{-}(\alpha \in(0,1))$ and $M$, which denote the guarantee fee and fixed management fee, at the beginning of year $t$, respectively. 


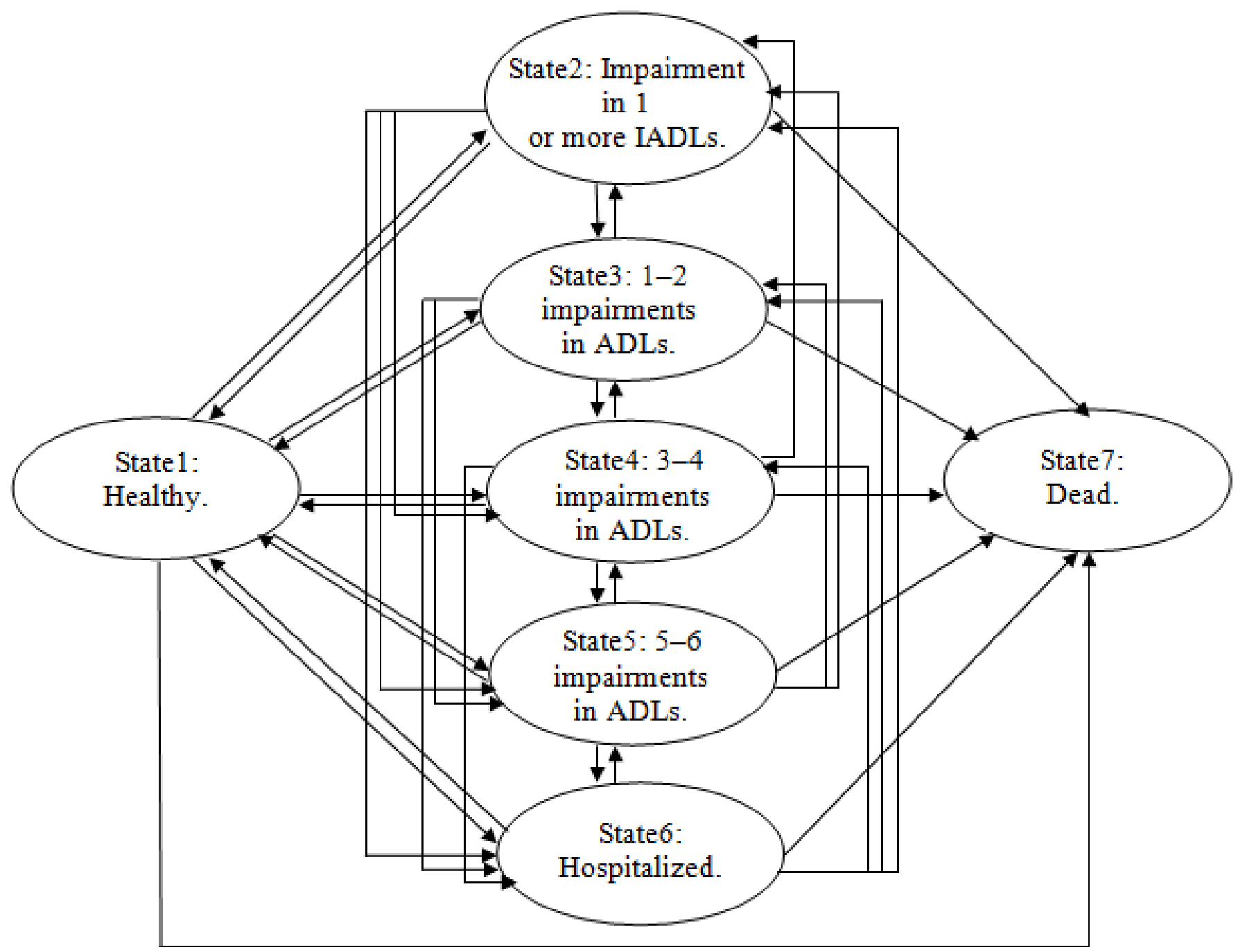

Figure 1: The health status of the policyholder.

Note that the invested amount, in the two investment funds, grows based on the constant interest rate $i$ and the return rate $R_{t}$ and reaches $W_{t}$ at time $t$.

Hereafter, it is assumed assume that account value which was invested in the risky fund $R F(t)$ at time $t$ follows the Geometric Brownian Motion (GBM), therefore its return rate $R_{t}$ holds

$$
R_{t}=\exp \left\{\left(\mu-\frac{\sigma^{2}}{2}\right)+\sigma\left(B_{t}-B_{t-1}\right)\right\}
$$

where $\mu$ and $\sigma^{2}$ are the expected drift rate and the volatility of the process, respectively, and $B_{t}$ 
denotes the standard Brownian motion process, see Shreve (2004) and Oksendal (2013) for more details.

\section{Theoretical representation of the product}

As discussed in the previous section, the insurer has three obligations: medical costs $S B_{t}^{x}$, hospitalization costs $H B_{t}^{x}$ and withdrawal benefits for its policyholder. This study assumes that medical costs of a policyholder who has bought the contract at age $x$ are non-zero only whenever the policyholder loses 3 or more ADLs. In the other word, $S B_{t}^{x}$ that is only paid to a policyholder who moves to state 4 or 5 during the period $[t-1, t)$ and is 0 otherwise, can be modeled by

$$
S B_{t}^{x}=\left\{\begin{aligned}
& 0 M_{x}(t)=\{1,2,3\} ; \\
& c w_{0}^{x}(1+\pi) \quad M_{x}(t)=\{4,5\} ;
\end{aligned}\right.
$$

where $c$ and $\pi$ are given positive constant and fixed inflation rate, respectively.

When a policyholder stays at the hospital during the period $[t-1, t)$ and moves to state 6 , the hospitalization costs $H B_{t}^{x}$ are paid to her/him. This study assumes that the hospitalization benefits are limited and have been provided up to $L$ days from the beginning of the contract; therefore, such reimbursement depends on two factors:

1) total number of hospitalization days for the policyholder at age $x+t$ who has bought the contract at age $x\left(\right.$ denoted by $\left.T_{t}^{x}\right)$, and

2) the number of years during which the policyholder, who has bought the contract at age $\mathrm{x}$, has received the hospitalization benefits (denoted by $D_{x}$ ).

It is obvious that modeling of the hospitalization days $T_{t}^{x}$ and the hospitalization benefits $D_{x}$ are the first steps for determining the hospitalization costs.

Suppose the counting process $N_{t}^{x}$ represents the number of hospitalization visits at the $t^{\text {th }}$ policy year. Moreover, suppose that the policyholder in her $/$ his $i^{\text {th }}$ visit at the $t^{\text {th }}$ policy year has stayed 
$M_{t, i}^{x}$ days in the hospital. Therefore, the hospitalization days for the policyholder at the policy year t are

$$
T_{t}^{x}=\sum_{i=1}^{N_{t}^{x}} M_{t, i}^{x} .
$$

For simplicity hereafter, it is assumed that the two counting processes $N_{t}^{x}$ and $M_{t, i}{ }^{x}$ are two independent Poisson processes with rates $\lambda_{N}$ and $\lambda_{M}$, respectively.

Considering that y shows the average age at which the total expected hospitalization days reaches $\mathrm{L}$ for the first time, the random number of years that the policyholder can be benefited from the hospitalization coverage is determined as follows:

$$
D_{x}=\inf \left\{y: \quad \sum_{t=1}^{y} E\left(T_{t}^{x}\right) \geq L\right\} .
$$

Hereafter, it is assumed that the daily payment for hospitalization at time $t$ is modeled by $b_{t}=$ $b(1+\phi)^{t}$; where $\phi$ and $b$ are a given inflation protection rate for medical costs and a given positive constant, respectively. Then $H B_{t}{ }^{x}$ can be formulated by

$$
H B_{t}{ }^{x}=\left(b_{t} T_{t}^{x}\right) I_{\left(0, D_{x}\right)}(t)+\left[\sum_{i=1}^{D_{x}} b_{i} L-\sum_{i=1}^{t-1} b_{i} T_{i}^{x}\right] I_{\left\{D_{x}\right\}}(t)+(0) I_{\left(D_{x}, \infty\right)}(t),
$$

where $I_{A}(t)$ is the indicator function. Given that a limitation has been taken into account for the number of hospitalization days for the product specified in the section 2, two different products can be designed considering this feature. Therefore, based on the expiration condition, the following two slightly different products can be considered. The following represents a mathematical model for product 1 .

Product 1. Suppose that a policyholder, at age $x$, pays $w_{0}^{x}$ and buys an insurance contract with assumptions from $A_{1}$ to $A_{4}$ that have been presented in the section 2. Additionally: (1) at time $t$, the insurer invests the $\delta$ percent of the investable amount in a risky fund with the return rate $R_{t}$ and the rest (i.e., the $1-\delta$ percent) in a risk-free fund with the constant interest rate $i$ and (2) the policy will be expired either when the policyholder dies (state 7) or his/her money reaches zero. 
Then, $W_{t}$, holds

$$
\begin{aligned}
& W_{0}^{-}=w_{0}^{x} ; \\
& W_{0}^{+}=\max \left\{W_{0}^{-}-\alpha W_{0}^{-}-M ; 0\right\} ; \\
& W_{t}^{-}=\delta \times W_{t-1}^{+} \times R_{t}+(1-\delta) \times W_{t-1}^{+} \times(1+i), \quad \forall t=1,2, \cdots, K_{x} ; \\
& W_{t}^{+}=\max \left\{W_{t}^{-}-\alpha W_{t}^{-}-M-G_{t}-H B_{t}^{x}-S B_{t}^{x} ; 0\right\}, \quad \forall t=1,2, \cdots, K_{x}-1 ; \\
& W_{K_{x}}^{+}=\max \left\{G_{K_{x}}+H B_{K_{x}}^{x}+S B_{K_{x}}^{x} ; W_{K_{x}}^{-}\right\},
\end{aligned}
$$

where $W_{t}^{-}$and $W_{t}^{+}$denote the account value at year $t$ before and after withdrawals, respectively. And the random positive integer number $K_{x}$ stands for death time of a policyholder who has bought the product at age $x$.

In order to find the fair value of this product, the expected present value of cash flows should be calculated. Therefore, the discounted cash flows (DCF) method at time $t$ is first used by a money market account $\gamma(t)$. Due to the risk-neutrality of $\gamma(t)$, the dynamics of $\gamma(t)$ can be given by the $\frac{d \gamma(t)}{\gamma(t)}=r d t$ and its solution is $\gamma(t)=\gamma(0) e^{r t}$, where $r$ is a given constant rate. Without loss of generality, suppose that $\gamma(0)=1$ and therefore $\gamma(t)=e^{r t}$. Based on this observation, the fair value of Product 1 can be expressed as

$$
E\left(\sum_{t=1}^{K_{x}} e^{-r t}\left(G_{t}+S B_{t}^{x}+H B_{t}^{x}\right)+E\left(e^{-r K_{x}} \max \left\{0 ; W_{K_{x}}^{-}-\left(G_{K_{x}}+S B_{K_{x}}^{x}+H B_{K_{x}}^{x}\right)\right\}\right)\right.
$$

where $E()$ denotes the expected value. Now, the product 1 is exposed to an extra expiration condition and the product 2 is introduced. The mathematical model for such product is represented below.

Product 2. Suppose that a policyholder, at age $x$, pays $w_{0}^{x}$ and buys an insurance contract with assumptions from $A_{1}$ to $A_{4}$ that have been presented in the section 2. Additionally: (1) at time $t$, the insurer invests $\delta$ percent of the investable amount in a risky fund with the return rate $R_{t}$, and the rest (i.e., $1-\delta$ percent) in a risk-free fund with the constant interest rate $i$, and (2) the policy will be expired either when the policyholder dies (state 7), or when s/he reaches the maximum hospitalization days $L$ at year $D_{x}$ or her/his invested amount reaches zero. 
Then, $W_{t}$ holds

$$
\begin{aligned}
& W_{0}^{-}=w_{0}^{x} ; \\
& W_{0}^{+}=\max \left\{W_{0}^{-}-\alpha W_{0}^{-}-M ; 0\right\} ; \\
& W_{t}^{-}=\delta \times W_{t-1}^{+} \times R_{t}+(1-\delta) \times W_{t-1}^{+} \times(1+i), \quad \forall t=1,2, \ldots, Y_{x} ; \\
& W_{t}^{+}=\max \left\{W_{t}^{-}-\alpha W_{t}^{-}-M-G_{t}-H B_{t}{ }^{x}-S B_{t}^{x} ; 0\right\}, \quad \forall t=1,2, \ldots, Y_{x}-1 ; \\
& W_{Y_{x}}^{+}=\max \left\{g_{Y_{x}}+H B_{Y_{x}}{ }^{x}+S B_{Y_{x}}^{x}, W_{Y_{x}}^{-}\right\}
\end{aligned}
$$

where $Y_{x}=\min \left\{D_{x}, K_{x}\right\}$ and $W_{t}^{-}, W_{t}^{+}$and $K_{x}$ have already been defined. Similar to the Product 1, the fair value of Product 2 can be calculated via the following equation

$$
E\left(\sum_{t=1}^{Y_{x}} e^{-r t}\left(G_{t}+S B_{t}^{x}+H B_{t}^{x}\right)+E\left(e^{-r Y_{x}} \max \left\{0 ; W_{Y_{x}}^{-}-\left(G_{Y_{x}}+S B_{Y_{x}}^{x}+H B_{Y_{x}}^{x}\right)\right\}\right)\right.
$$

where $E()$ denotes the expected value.

\section{Data Explanation}

Since solving two Equation (8) and Equation (10) is highly time-consuming and complex, the Monte Carlo algorithm is employed to calculate fair value of these products. Algorithm 1 represents the simulation algorithm in the present study for $A$ times replication. For the simulation study, assume that the number of replications is equal to $A=10000$, fixed payment for hospitalization days is equal to $b=2000$, management fees is equal to $M=300$, two constants are equal to $c=0.06$ and $\beta=0.02$, guaranteed fees are equal to $\alpha=0.008$, and inflation rates for medical and hospitalization costs are equal to $\pi=0.05$ and $\phi=0$. The interest rate $r$ in the discounting equation $\gamma(t)$ is equal to 0.040811 , and two intensity rates are equal to $\lambda_{N}=0.3$ and $\lambda_{M}=12.3$. Moreover, it is assumed that the mean and standard deviation of the GBM process are equal to 0.5 and 0.1 , respectively. The interest rate is equal to $i=5 \%$ and $\delta=0.7$. Figure 2 shows return rates of the two investment funds that are assumed in this study.

The R software (version 3.6.3) and packages markovchain, actuar, mgcv, car and MASS have been employed for the simulation study. The $\mathrm{R}$ codes are provided on request. 


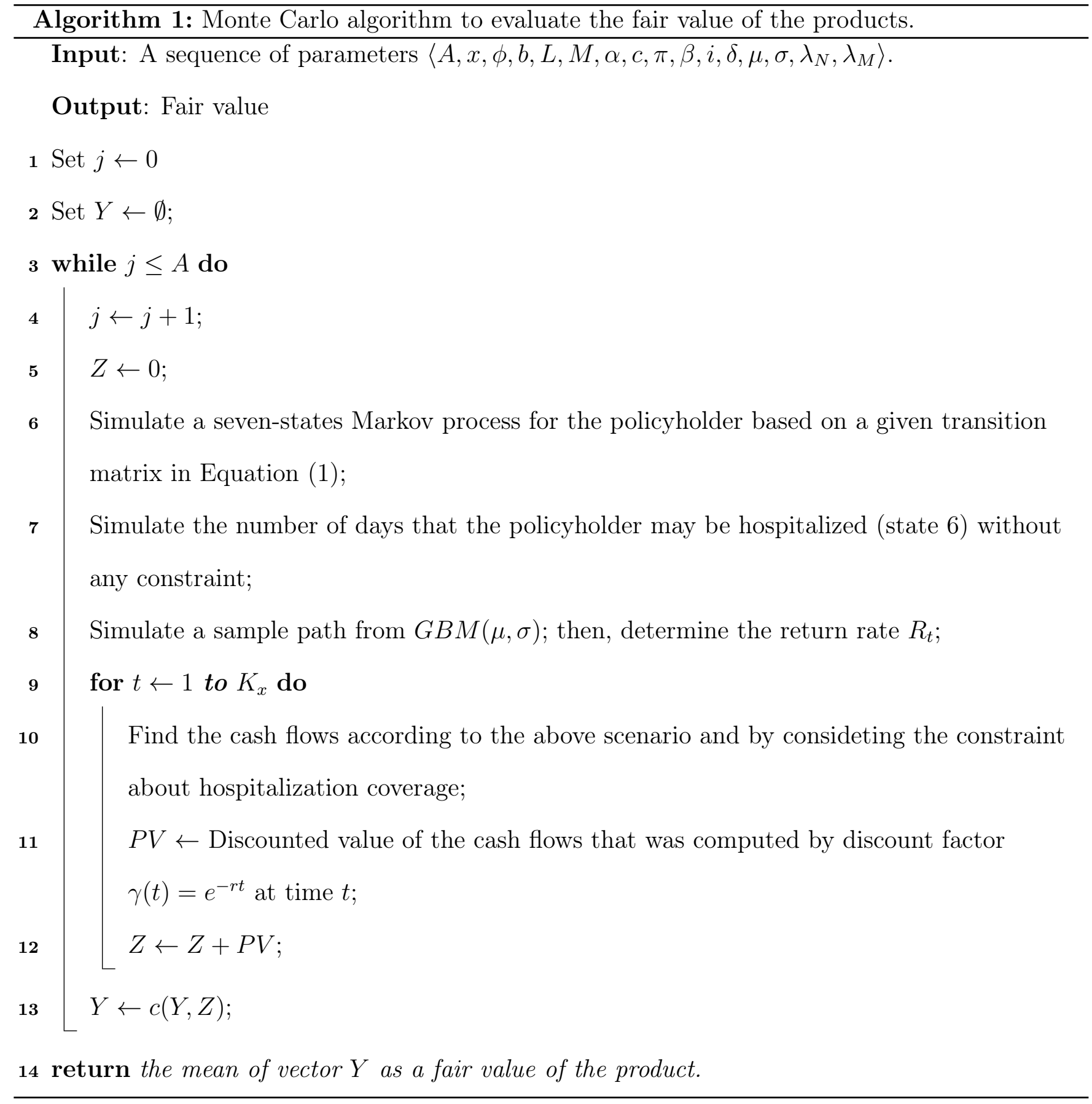




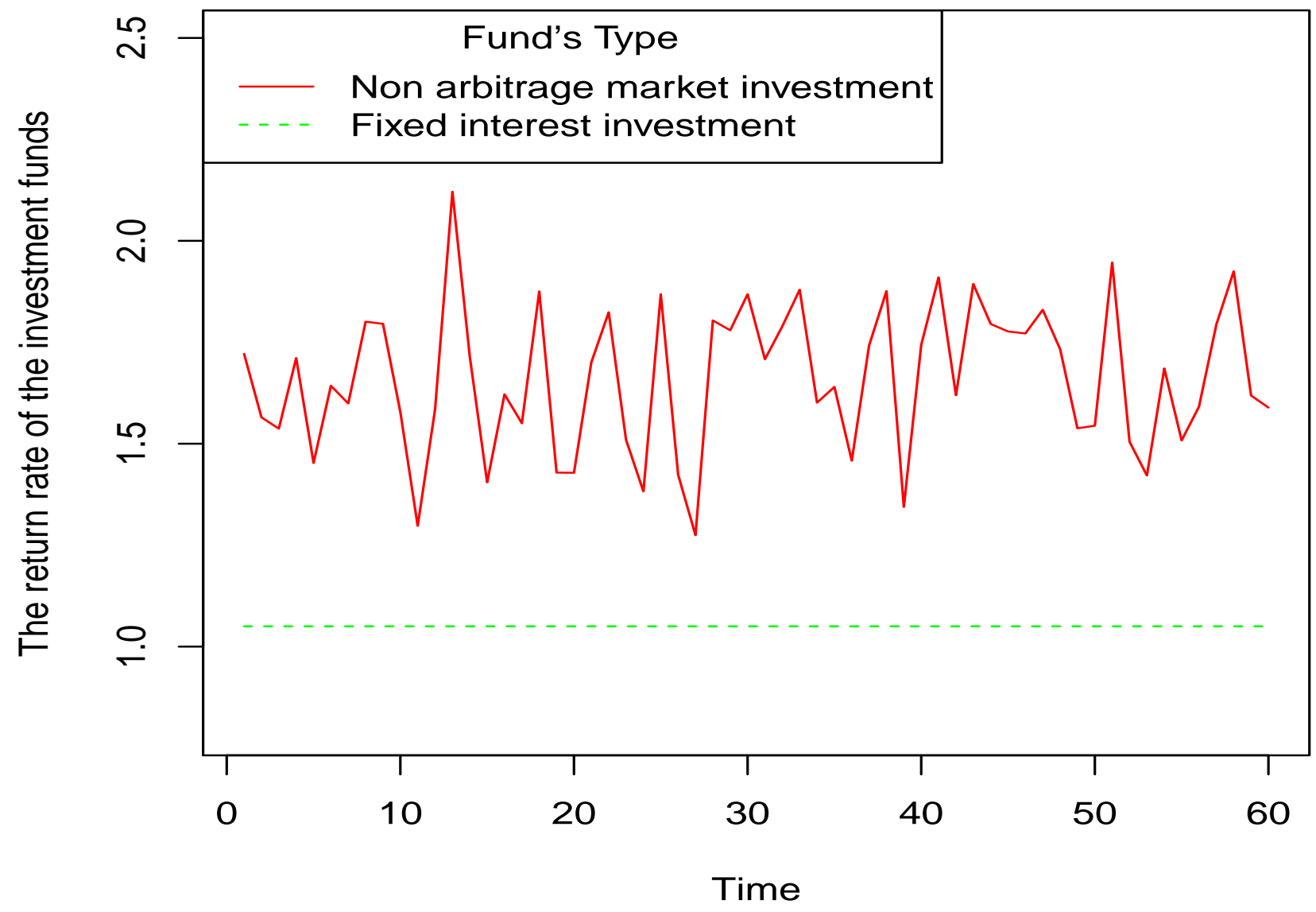

Figure 2: Return rates of the two investment funds.

\section{Numerical Results}

Now using the assumptions in section 4, fair value of Product 1 and product 2 are calculated. Table 1 and Figure 3 represent fair value of the two products under the above assumptions.

Since increasing the policyholder's entrance age increases the medical costs, it is expected that the fair value of both products will be enhanced as the age is increased. In addition, since Product 1 provides benefits for a longer time, therefore, its fair value is higher than the Product 2. Table 1 and Figure 3 verifiy this expectation and show that as the entrance age increases, the fair value of 
Table 1: The fair values of two products for different entrance ages.

\begin{tabular}{c|ccccc}
\hline & \multicolumn{5}{|c}{ Entrance age of policyholder } \\
\hline & $\mathrm{X}=60$ & $\mathrm{X}=65$ & $\mathrm{X}=70$ & $\mathrm{X}=75$ & $\mathrm{X}=80$ \\
\hline Product 1 & 253103.1 & 271074.7 & 281807.5 & 285078.2 & 288786.4 \\
\hline Product 2 & 238436.9 & 258028.7 & 270380.1 & 275469.5 & 279833.8 \\
\hline
\end{tabular}

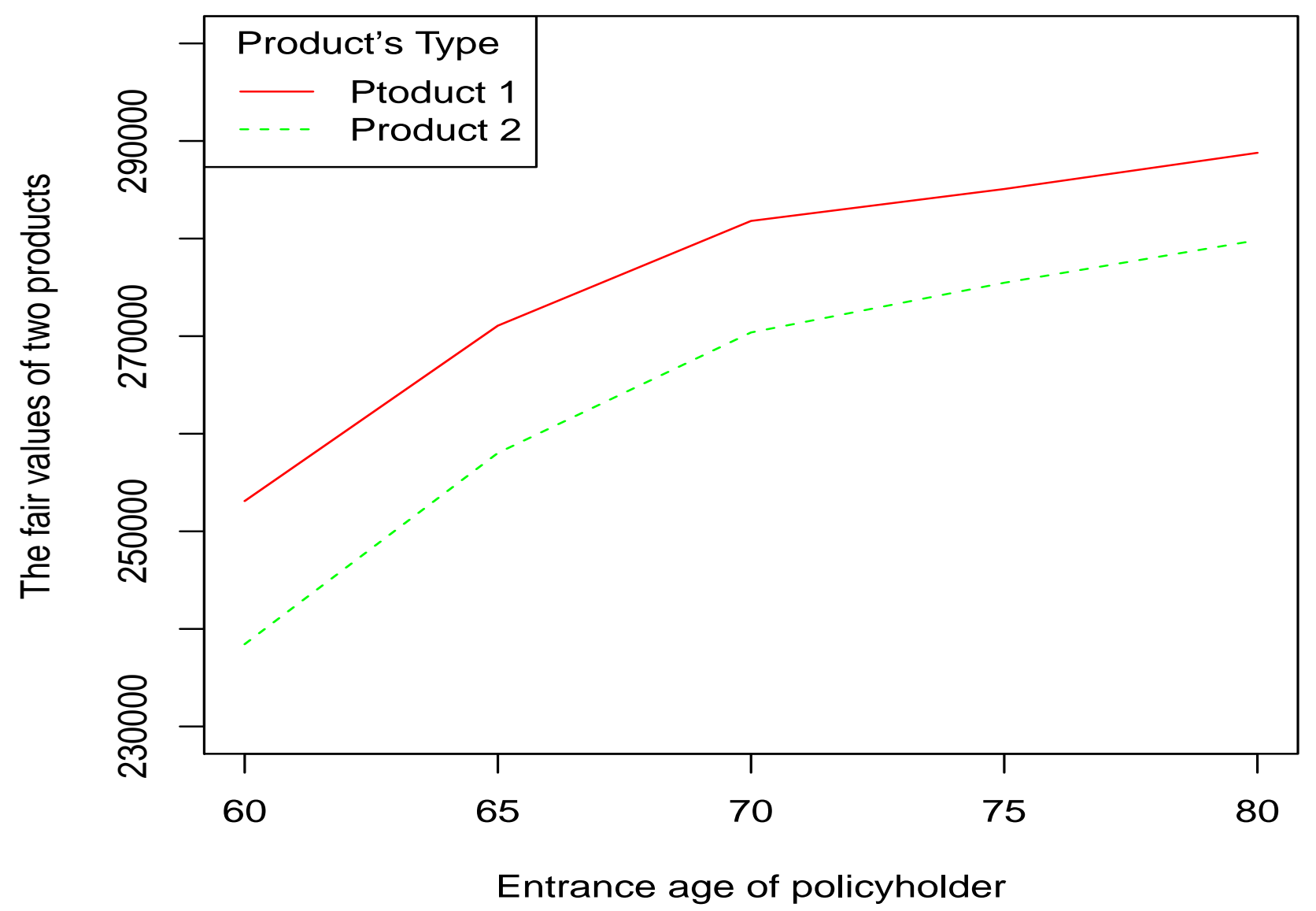

Figure 3: Fair values of two products for different entrance ages.

both products is increased and the product 2 is less expensive than the product 1 . Also, Figure 3 shows the pattern of fair value for both products as a function of the policyholder's age.

Both products have $L$ day hospitalization benefits. Certainly, such hospitalization day is effective 
on the fair value of both products. To illustrate such effect, consider a policyholder who bought the products at age 60 and suppose that the total hospitalization days $L$ can be varied between 20 to 200 days. Figure 4 illustrates the effect of $L$ on fair values of the two products.

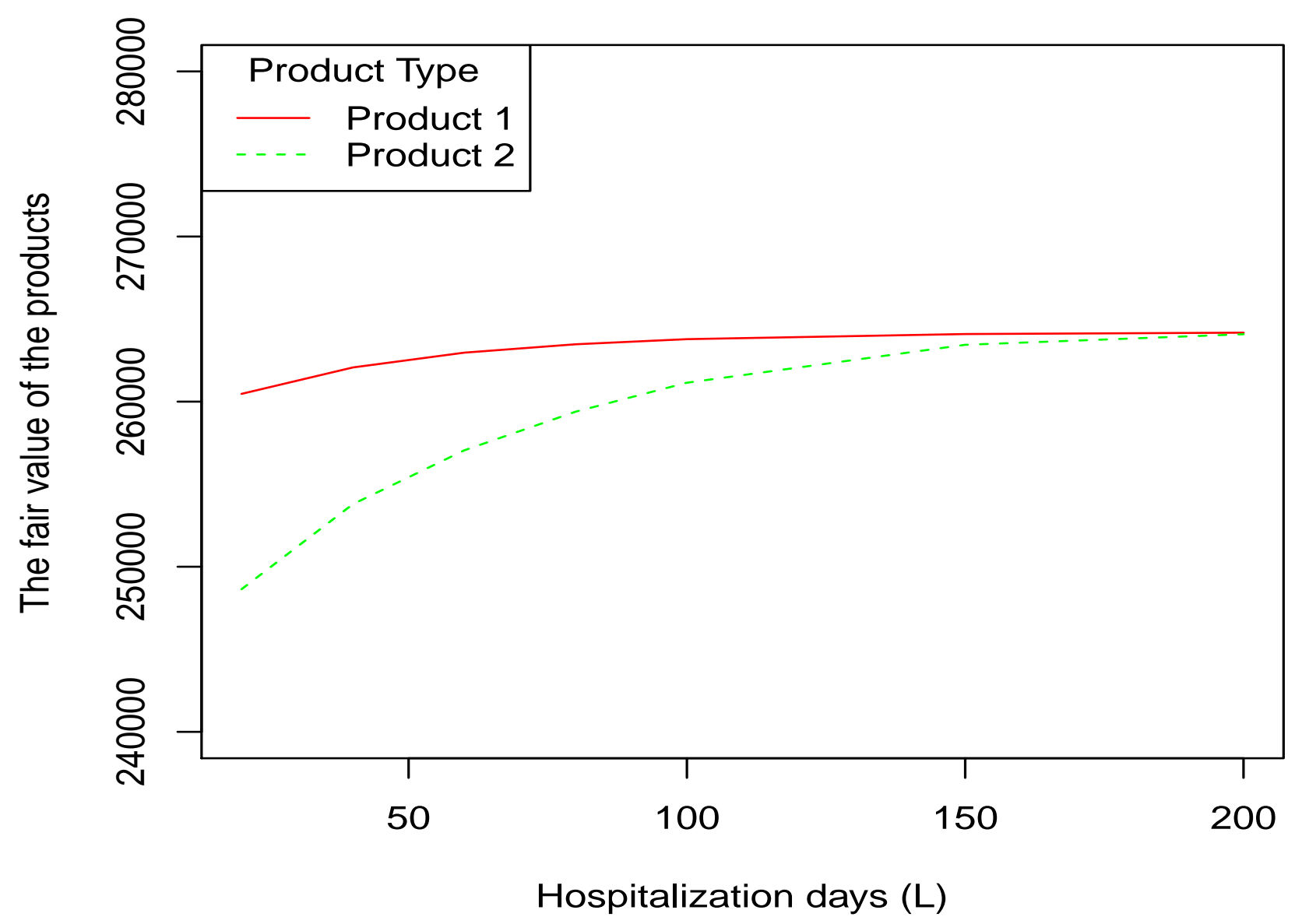

Figure 4: The fair values of two products for different Hospitalization days for a policyholder who bought the products at age of 60 .

As it is expected, the length of hospitalization days $L$ is effective on the fair value of both products directly. Furthermore, when $L$ is increased, fair value of these products has a similar behavior. This observation can be due to that fact that the account value is relatively small for large $L$ and the difference between fair values of the two products is very small. 
Table 2: The fair values of two products for different "withdrawal benefit" rate $\beta$ whenever entrance age is 60 .

\begin{tabular}{l|cccccc}
\hline & \multicolumn{5}{|c}{ Coefficient $\beta$ of "withdrawal benefit" rate } \\
\hline & $\beta=0.005$ & $\beta=0.01$ & $\beta=0.015$ & $\beta=0.02$ & $\beta=0.025$ & $\beta=0.03$ \\
\hline Product 1 & 242548.6 & 247933.3 & 253651.3 & 259258.1 & 264706.8 & 270217.3 \\
\hline Product 2 & 227422.4 & 232807.1 & 238525.0 & 244131.9 & 249580.6 & 255091.1 \\
\hline
\end{tabular}

Table 3: The fair values of two products for different $\delta$ whenever entrance age is 60 .

\begin{tabular}{l|cccccc}
\hline & \multicolumn{6}{|c}{ Coefficient $\delta$} \\
\hline & $\delta=0.15$ & $\delta=0.3$ & $\delta=0.45$ & $\delta=0.6$ & $\delta=0.75$ & $\delta=0.9$ \\
\hline Product 1 & 209375.0 & 222006.7 & 234776.0 & 247590.5 & 260533.9 & 272671.0 \\
\hline Product 2 & 194451.0 & 207082.6 & 219851.9 & 232666.4 & 245609.9 & 257746.9 \\
\hline
\end{tabular}

The random "withdrawal benefit" rate $G_{t}$ is another factor that may influence the fair value of the products. This study assumes that the policyholder withdraws the random amount $G_{t}$ that has been selected from the interval $\left(0, \beta w_{0}^{x}\right)$ at the beginning of year $t$. Since increasing the "withdrawal benefit" rate $G_{t}$ increases the benefits that have been received by the policyholder directly, it is expected that when $\beta$ is increased, the fair value of both products will be increased too. Suppose a policyholder who buys the products at age 60 with the limitation $L=10$ days.

Table 2 shows the effect of the coefficient $\beta$ in "withdrawal benefit" on the fair value of products and verifies the above anticipation.

As mentioned earlier, $\delta \%$ represents the investment rate in a arbitrage free investment fund and $(1-\delta) \%$ represents the investment rate in a risk-free investment fund with the interest rate $i$. It is obvious that the fair value of both products is influenced by the value of $\delta$. Figure 2 shows that the return rate under the GBM process is greater than the risk-free investment fund. Therefore, it is expected that fair value of both products will be increased when $\delta$ is increased. Table 3 shows the effect of $\delta$ on the fair value of our products.

The current study assumes that $(1-\delta) \%$ of the account value is invested with a fixed interest rate. 
Table 4: The fair values of two products for different constant interest rate $i$ whenever entrance age is 60 .

\begin{tabular}{l|cccccc}
\hline & \multicolumn{6}{|c}{ Constant interest rate $i$} \\
\hline & $i=0.03$ & $i=0.06$ & $i=0.09$ & $i=0.12$ & $i=0.15$ & $i=0.18$ \\
\hline Product 1 & 258762.8 & 260062.6 & 261362.3 & 262662.1 & 263961.8 & 265261.6 \\
\hline Product 2 & 243636.6 & 244936.4 & 246236.1 & 247535.9 & 248835.6 & 250135.3 \\
\hline
\end{tabular}

Table 5: The relationship between the fair value of the products, $\phi$ and $\pi$ for 60 -aged insured under the GBM process.

\begin{tabular}{|c|cccc|cccc|}
\hline & \multicolumn{5}{|c|}{ Product 1 } & \multicolumn{4}{c|}{ Product 2 } \\
\hline$\pi$ & $\phi=0.01$ & $\phi=0.02$ & $\phi=0.03$ & $\phi=0.04$ & $\phi=0.01$ & $\phi=0.02$ & $\phi=0.03$ & $\phi=0.04$ \\
\hline 0.01 & 252582.1 & 253943.2 & 255539.1 & 257425.4 & 243752.8 & 243941.1 & 244135.9 & 244337.4 \\
\hline 0.02 & 252626.8 & 253987.9 & 255583.8 & 257470.1 & 243797.5 & 243985.8 & 244180.6 & 244382.1 \\
\hline 0.03 & 252673.2 & 254034.3 & 255630.2 & 257516.5 & 243843.9 & 244032.2 & 244226.9 & 244428.5 \\
\hline 0.04 & 252721.3 & 254082.5 & 255678.4 & 257564.6 & 243892.1 & 244080.4 & 244275.1 & 244476.7 \\
\hline
\end{tabular}

Thus, it is obvious that the constant interest rate $i$ effective on the fair value of the products too. In Table 4, the effect of $i$ on fair value of these two products has been analyzed. In this table, $i$ varies from $3 \%$ to $18 \%$ and policyholder's entrance age is 60 . Table 4 illustrates that as the interest rate $i$ is increased, the fair value of both products will be increased too.

Up to now, the inflation rate for hospitalization cost over time has been assumed equal to zero (e.g. $\phi=0)$. Now, the effect of the two inflation rates $\pi$ and $\phi$ on fair value of both products is analyzed. Consider a policyholder who buys the products at age 60 with the limitation $L=10$ days. Table 5 shows such effect. As expected, the fair value of products has directly been influenced by two inflation rates $\pi$ and $\phi$. This finding can be interpreted by the fact that increasing such inflation rates will directly increase the benefits that have been paid to the policyholder and consequently fair value of both products is increased. 


\section{Conclusion and suggestions}

The present study proposed and evaluated two new products, i.e. the variable annuity products that have been accompanied by a long-term care coverage, limited hospitalization coverage and a guaranteed lifelong withdrawal benefit option. At the beginning of each product, an x year old policyholder pays the lump sum $w_{0}^{x}$ and the insurer invests it in two investment funds with both random and constant interest rates. After withdrawing the costs by the insurer, the policyholder

receives benefits like constant medical cost coverage, limited hospitalization cost coverage, and random withdrawal benefits. As mentioned earlier, all features of these products are similar except their expiration conditions.

These products may provide a more comprehensive solution for the aging problem of the population that is challenging in the current societies. These products may be more attractive whenever the medical cost and hospitalization cost are increased over time with a more reasonable model. For instance, using the medical health care cost models that have been developed by Christiansen et al. (2018) and Piontkowski (2019), the limitation on medical cost $b_{t}$ can be removed in this study. The next study has assumed that the age of the patient and the time he/she refers to receive medical services are effective on the average health costs and has suggested an stochastic model for the expected health expenses. Hence, given this model, health expenses can be estimated more accurately and health insurance products will be designed more precisely.

\section{Compliance with Ethical Standards}

Funding: There is no financial support for the study.

Authors declare that they have no conflict of interest.

Ethical approval: This study does not contain any studies with human participants or animals performed by any of the authors. 


\subsection{Acknowledgements}

We would like to thank referees whose helpful comments led to substantial improvements in this paper.

\section{References}

[1] Albarran, I., Ayuso, M., Guillén, M., and Monteverde, M. (2005). A multiple state model for disability using the decomposition of death probabilities and cross-sectional data. Communications in Statistics-Theory and Methods, 34(9-10), 2063-2075.

[2] Asmussen, S., and Glynn, P. W. (2007). Stochastic Simulation: algorithms and analysis (Vol. 57). Springer Science \& business Media.

[3] Baione, F., and Levantesi, S. (2014). A health insurance pricing model based on prevalence rates: Application to critical illness insurance. Insurance: Mathematics and Economics, 58, $174-184$.

[4] Bernard, G. A. (2010). Measuring the value of a guaranteed lifetime withdrawal benefit. Journal of Financial Service Professionals, 64(2), 38-43.

[5] Brown, J., and Warshawsky, M. (2013). The life care annuity: A new empirical examination of an insurance innovation that addresses problems in the markets for life annuities and longterm care insurance. Journal of Risk Insurance, 80(3), 677-704.

[6] Christiansen, M., Denuit, M., Lucas, N., and Schmidt, J. P. (2018). Projection models for health expenses. Annals of Actuarial Science, 12(1), 185-203. 
[7] Cochran, J. K., and Bharti, A. (2006). A multi-stage stochastic methodology for whole hospital bed planning under peak loading. International Journal of Industrial and Systems Engineering, 1(1-2), 8-36.

[8] D’Amato, V., Levantesi, S., Menzietti, M. (2020). De-risking long-term care insurance. Soft Computing, 24, 8627-8641.

[9] Di Palo, C. (2020). Tackling longevity risk by means of financial compensation. Soft Computing, bf 24(12), 8583-8597.

[10] Glasserman, P. (2004). Monte Carlo methods in financial engineering (Vol. 53). Springer Science \& Business Media.

[11] Haberman, S., and Pitacco, E. (1998). Actuarial models for disability insurance. CRC Press, Florida.

[12] Hsieh, M.h., Wang, J. L., Chiu, Y.F., and Chen, Y.C. (2018). Valuation of variable long-term care annuities with Guaranteed Lifetime Withdrawal Benefts: A variance reduction approach. Insurance: Mathematics and Economics, 78, 246-254.

[13] Holz, D., Kling, A., Russ, J. (2012). GMWB for life: An analysis of lifelong withdrawal guarantees. Zeitschrift für die Gesamte Versicherungswissenschaft, 101(3), 305-325.

[14] Levantesi, S., and Menzietti, M. (2012). Managing longevity and disability risks in life annuities with long term care. Insurance: Mathematics and Economics, 50(3), 391-401.

[15] Manton, K. G., Corder, L. S., and Stallard, E. (1993). Estimates of change in chronic disability and institutional incidence and prevalence rates in the US elderly population from the 1982, 1984, and 1989 National Long Term Care Survey. Journal of Gerontology, 48(4), 153-166.

[16] Migon, H. S., and Moura, F. A. (2005). Hierarchical bayesian collective risk model: an application to health insurance. Insurance: Mathematics and Economics, 36(2), 119-135. 
[17] Murtaugh, C. M., Spillman, B. C., and Warshawsky, M. J. (2001). In sickness and in health: An annuity approach to fnancing long-term care and retirement income. Journal of Risk and Insurance, 68(2), 225-253.

[18] Oksendal, B. (2013). Stochastic Differential Equations: An Introduction with Applications. Springer Science \& Business Media.

[19] Orji, I. M. J., Akanbi, O., and Wei, S. (2015). Cost modelling in healthcare systems: a case of radiology department of a teaching hospital. International Journal of Industrial and Systems Engineering, 19(1), 50-74.

[20] Piscopo, G. (2009). The fair price of guaranteed lifelong withdrawal benefit option in variable annuity. Problems and Perspectives in Management, 7(4), 79-83.

[21] Piscopo, G., Haberman, S. (2011). The valuation of guaranteed lifelong withdrawal benefit options in variable annuity contracts and the impact of mortality risk. North American Actuarial Journal, 15(1), 59-76.

[22] Pitacco, E. (2014). Health Insurance: Basic Actuarial Models. Springer Science \& Business Media.

[23] Pitacco, E. (2013). From Benefits to Guarantees: Looking at Life Insurance Products in a New Framework. Available at SSRN: https://ssrn.com/abstract=2200310 or http://dx.doi.org/10.2139/ssrn.2200310.

[24] Pitacco, E. (1995). Actuarial models for pricing disability benefits: Towards a unifying approach. Insurance: Mathematics and Economics, 16(1), 39-62.

[25] Piontkowski, J. (2019). Forecasting health expenses using a functional data model. Annals of Actuarial Science, 1-11. 
[26] Pritchard, D. J. (2006). Modeling disability in long-term care insurance. North American Actuarial Journal, 10(4), 48-75.

[27] R Development Core Team (2011). R: A language and environment for statistical computing. R Foundation for Statistical Computing, Vienna, Austria. ISBN 3-900051-07-0, URL http://www.R-project.org/.

[28] Rosenberg, M. A., and Farrell, P. M. (2008). Predictive Modeling of Costs for a Chronic Disease With Acute High-Cost Episodes. North American Actuarial Journal, 12(1), 1-19.

[29] Shreve, S. E. (2004). Stochastic calculus for finance II: Continuous-time models (Vol. 11). Springer Science \& Business Media.

[30] Tessera, A. (2007). Probabilistic models for medical insurance claims. Applied Stochastic Models in Business and Industry, 23(4), 307-317.

[31] Webb, D. C. (2009). Asymmetric Information, Long Term Care Insurance, and Annuities: The Case for Bundled Contracts. Journal of Risk Insurance, 76(1), 53-85.

[32] Weng, S. J., Wu, T., Mackulak, G. T., and Verdivi, W. A. (2012). A multi-tool integrated methodology for distributed resource allocation in healthcare. International Journal of Industrial and Systems Engineering, 11(4), 428-452.

[33] Yang, S. Y., Wang, C. W., and Huang, H. C. (2016), The valuation of lifetime health insurance policies with limited coverage. Journal of Risk and Insurance, 83(3), 777-800. 